\title{
PEMANFAATAN DAN PENGELOLAAN KAWASAN KONSERVASI LAUT DAERAH GILI SULAT DAN GILI LAWANG
}

\author{
Hakim Miftakhul Huda dan Yesi Dewita Sari ${ }^{1}$ \\ ${ }^{1}$ Peneliti pada Balai Besar Riset Sosial Ekonomi Kelautan dan Perikanan \\ JI. KS Tubun Petamburan VI Jakarta 10260. \\ Telp. (021)53650162, Fax. (021)53650159 \\ Diterima 24 Maret 2010 - Disetujui 26 Juni 2010
}

\begin{abstract}
ABSTRAK
Tingginya intensitas aktivitas penangkapan ikan telah menyebabkan degradasi sumber daya ikan pada beberapa daerah penangkapan ikan. Salah satu langkah untuk menjaga keberlanjutan dan meminimalkan degradasi sumber daya ikan adalah membentuk kawasan konservasi laut daerah. Penelitian ini bertujuan untuk mengetahui pemanfaatan dan pengelolaan Kawasan Konservasi Laut Daerah (KKLD) Gili Sulat-Gili Lawang, Provinsi Nusa Tenggara Barat. Penelitian menggunakan metode valuasi ekonomi sumber daya untuk menganalisis gabungan data primer dan sekunder. Hasil penelitian menunjukkan total nilai manfaat KKLD Gili Sulat-Gili Lawang adalah Rp 8,99 milyar per tahun yang meliputi manfaat langsung dan tidak langsung. Hasil penelitian menunjukan pengelolaan terhadap KKLD ditinjau dari biaya, aktor atau pelaku dan aktivitas pengelolaan sampai saat ini belum optimal. Penelitian ini menyarankan perlunya menyusun strategi pengelolaan yang tepat untuk mengoptimalkan maksud dan tujuan dibentuknya KKLD.
\end{abstract}

Kata kunci: valuasi ekonomi, konservasi laut, KKLD Gili Sulat-Gili Lawang

\section{Abstract: Utilization and Management of The Gili Sulat and The Gili Lawang Regional Marine Conservation Area . By: Hakim Miftakhul Huda and Yesi Dewita Sari}

Highly intensive of fishing activities lead to degradation of fish resources in some fishing grounds. One effort to maintain sustainability of fish resources and minimize its degradation is to establish local marine conservation areas. This study aims to analyze utilization and management of Gili Sulat-Gili Lawang local marine conservation areas (or locally known as KKLD) in Wes Nusa Tenggara Province. This study applies economic valuation methods to analyze combination of primary and secondary data. Results of this study show that annual total benefit values of Gili Sulat-Gili Gili Lawang KKLD is IDR 8,99 billion which includes direct and indirect benefits. In terms of costs, actors and management activities, current management of KKLD is less optimal. Therefore, this study recommends to develop appropriate management strategies to optimize the purposes of KKLD establishment.

Keywords : economic valuation, marine conservation, KKLD Gili Sulat-Gili Lawang 


\section{PENDAHULUAN}

Salah satu upaya untuk menjaga kelestarian sumber daya perikanan adalah membuat sebuah kawasan konservasi sumber daya perairan atau suaka perikanan. Kawasan konservasi perairan merupakan bagian pengelolaan atau konservasi lingkungan sumber daya perairan. Keberadaan kawasan konservasi memegang peranan penting dalam mengimbangi kegiatan eksploitatif maupun terdegradasinya sumberdaya sebagai akibat dari berbagai aktivitas manusia. Berdasarkan tipe ekosistem yang dimiliki, kawasan konservasi perairan dapatdibedakan menjadi: kawasan konservasi perairan tawar, perairan payau atau perairan laut. Kawasan konservasi di wilayah perairan laut tersebut dikenal sebagai kawasan konservasi laut (KKL). Dalam pengembangannya, kawasan konservasi perairan di wilayah laut yang dikembangkan oleh pemerintah daerah sering disebut sebagai Kawasan Konservasi Laut Daerah (KKLD)

Kawasan konservasi mempunyai fungsi sebagai perlindungan terhadap sistem penyangga kehidupan, pengawetan keanekaragaman jenis flora dan fauna dimana ikan termasuk didalamnya. Konservasi sumber daya ikan, seperti yang tercantum dalam Undang-undang No. 31 Tahun 2004 pasal 1 ayat 8 tentang perikanan, mempunyai pengertian sebagai upaya perlindungan, pelestarian, dan pemanfaatan sumber daya ikan, termasuk ekosistem, jenis dan genetik untuk menjamin keberadaan, ketersediaan dan kesinambungannya dengan tetap memelihara dan meningkatkan kualitas nilai dan keanekaragaman sumber daya ikan. Menurut Peraturan Pemerintah Nomor 60 Tahun 2007 tentang konservasi sumber daya ikan, Konservasi Sumber Daya Ikan dilakukan pada tatanan ekosistem, jenis ikan dan genetik. Selanjutnya disebutkan bahwa penerapan konservasi ekosistem tersebut dilakukan melalui kegiatan: (1) Perlindungan habitat dan populasi ikan; (2) Rehabilitasi habitat dan populasi ikan; (3) Penelitian dan pengembangan; (4) Pemanfaatan sumber daya ikan dan jasa lingkungan; (5) Pengawasan pengendalian, dan (6) Monitoring dan evaluasi.

Sejauh ini, sangat sedikit informasi yang dapat dikumpulkan berkaitan dengan tingkat pemanfaatan kawasan konservasi perikanan. Informasi yang ada lebih banyak mengungkapkan manfaat bio ekologisnya saja, sedangkan manfaat sosial dan ekonomi terkait dengan kawasan konservasi belum banyak diungkap. Berdasarkan hal tersebut, perlu dilakukan penelitian yang mengkaji pemanfaatan dan pengelolaan Kawasan kKonservasi Laut Daerah (KKLD). Penelitian ini bertujuan untuk mengetahui pemanfaatan dan pengelolaan Kawasan Konservasi Laut Daerah (KKLD) Gili Sulat-Gili Lawang Nusa Tenggara Barat.

\section{METODOLOGI}

\section{Kerangka Pemikiran dan Ruang Lingkup Riset}

Kawasan konservasi memberikan banyak manfaat bagi kehidupan manusia. Manfaat tersebut dapat dilihat dari aspek biologi, aspek ekonomi dan aspek sosial. Secara keseluruhan aspek ini dapat dirasakan dalam jangka panjang. Manfaat dari aspek biologi seperti perlindungan terhadap keanekaragaman hayati, hubungan jaringan makanan serta proses-proses ekologis suatu ekosistem. Contoh pada perikanan tangkap, manfaat dari aspek biologi adalah adanya perlindungan terhadap daerah pemijahan, pembesaran dan daerah mencari makan, sehingga reproduksi dan stok perikanan dapat meningkat. Manfaat dari aspek ekonomi seperti adanya peningkatan penerimaan nelayan karena adanya peningkatan jumlah produksi, peningkatan kualitas sumber daya perikanan, adanya sumber pendapatan baru bagi masyarakat dengan memanfaatkan kawasan konservasi sebagai tempat pariwisata. Manfaat dari aspek sosial seperti memperluas pengetahuan dan pemahaman 
masyarakat terhadap ekosistem, meningkatkan keharmonisan antar masyarakat dan meningkatkan kepercayaan diri masyarakat terhadap pengelolaan sumber daya yang lestari.

Manfaat kawasan konservasi tersebut juga dapat dibedakan menjadi manfaat yang dapat terukur (tangible) dan manfaat yang tidak terukur (intangible). Manfaat terukur biasanya dikatakan juga manfaat kegunaan, baik yang dikonsumsi maupun tidak, sedangkan manfaat tidak terukur adalah manfaat bukan kegunaan berupa pemeliharaan dan perlindungan terhadap ekosistem. Manfaat dari aspek biologi, sebagian besar dapat digolongkan pada manfaat yang tidak terukur. Manfaat yang diidentifikasi dalam penelitian ini untuk kawasan konservasi laut terdiri dari manfaat langsung dari pemanfaatan perikanan, dan kegiatan pariwisata serta manfaat tidak langsung dari perlindungan terhadap pantai dan nilai estetika dari keanekaragaman hayati.

Dalam pemanfaatan sumber daya diperlukan suatu pengelolaan, supaya pemanfaatan yang dilakukan sesuai dengan tujuan dari dibentuknya atau ditetapkannya kawasan konservasi tersebut. Pengelolaan ini terkait dengan pelaku/aktor, aktivitas dan biaya-biaya yang timbul karena pelaksanaanya. Pelaku atau pengelola dari kawasan konservasi ini dapat dibedakan menjadi pelaku pemerintah dan masyarakat. Pemerintah dapat berupa pemerintah pusat dalam hal ini departemen maupun pemerintah daerah, baik ditingkat propinsi maupun kabupaten. Masyarakat dapat dikelompokkan menjadi individu, kelompok dan organisasi. Masyarakat juga dapat digolongkan berdasarkan kepentingannya, yaitu masyarakat pelaku penangkapan, pelaku pariwisata, pelaku ilmu pengetahuan dan teknologi, serta pelaku lainnya. Aktivitas pengelolaan dapat dibedakan menjadi aktivitas perencanaan, pelaksanaan dan pengawasan. Biaya-biaya yang timbul karena adanya kawasan konservasi terdiri dari biaya investasi, biaya operasional serta biaya lainnya seperti biaya transaksi dan biaya sosial.

Manfaat yang diidentifikasi dan diketahui dari penelitian ini dengan menggunakan teknik valuasi ekonomi. Data untuk analisis diperoleh dari data primer dan data sekunder. Biayabiaya dalam pengelolaan diperoleh melalui wawancara dengan pegawai dinas perikanan dan kelautan Kabupaten Lombok Timur dan beberapa data sekunder pendukung seperti hasil kajian terdahulu.

\section{Lokasi dan Waktu Penelitian}

Penelitian ini dilakukan pada Kawasan Konservasi Laut Daerah Gili Sulat dan Gili Lawang di Kabupaten Lombok Timur, Nusa Tenggara Barat pada bulan Juli - Oktober tahun 2009.

\section{Jenis dan Sumber Data}

Penelitian ini menggunakan data sekunder dan data primer. Data sekunder berasal dari laporan, dan publikasi lainnya yang terkait dengan laporan tahunan provinsi Nusa Tenggara Barat, data Badan Pusat Statistik, Kemeterian Kelautan dan Perikanan, dan data hasil penelitian sebelumnya, dan lain-lain. Data sekunder antara lain peraturan yang terkait dengan penetapan kawasan konservasi, batas-batas masing-masing wilayah atau peruntukan dan jumlah produksi perikanan. Data primer diperoleh dari hasil wawancara dengan nelayan atau wisatawan yang diantaranya adalah data mengenai jenis mata pencaharian, jumlah produksi, alat yang digunakan, investasi yang ditanamkan, biayabiaya yang dikeluarkan, keinginan membayar, serta beberapa data lainnya terkait dengan tujuan penelitian ini.

\section{Metode Pengumpulan Data}

Pengumpulan data primer dilakukan dengan cara pengamatan lapangan, wawancara individual mendalam dengan informan, wawancara terhadap responden dengan bantuan kuesioner dan diskusi informal. Penentuan responden dilakukan 
secara purposive sampling dengan mempertimbangkan aktivitas responden sebagai pelaku wisata atau nelayan yang terkait dengan KKLD Gili Sulat dan Gili Lawang. Pengumpulan data sekunder diperoleh melalui kajian literatur.

\section{Metode Analisis Data}

Metode analisis data yang dilakukan dalam penelitian ini adalah metode deskriptif berbasis tabulasi dengan pendekatan kuantitatif dan kualitatif. Pengolahan data dilakukan dengan proses pembersihan, entri, editing dan analisis data serta verifikasi data. Analisis kuantitatif dilakukan untuk mengetahui manfaat yang dapat diperoleh karena adanya kawasan konservasi tersebut serta biaya pengelolaan kawasan tersebut sebagai kawasan konservasi.

\section{Analisis Total Manfaat}

Untuk mengetahui total manfaat dari kawasan konservasi dilakukan dengan penjumlahan nilai::

$$
\mathrm{TB}=\sum_{i=1}^{3} B_{i}
$$

Keterangan :

$\mathrm{TB}=$ Total manfaat kawasan konservasi / Total benefit of conservation area

$B_{1}=$ Manfaat langsung ekstraktif perikanan/ Direct use of extractive fisheries

$B_{2}=$ Manfaat langsung non ekstraktif perikanan/ Indirect use of non extractive fisheries

$\mathrm{B}_{3}=$ Manfaat pilihan langsung/ Option benefit direct use

Teknik Valuasi yang digunakan untuk menghitung manfaat kawasan konservasi adalah Effect On Production (EOP) dan Travel Cost Method (TCM).

\section{A. Effect on Production (EOP)}

Nilai manfaat langsung diperoleh dengan menggunakan pendekatan harga yang diterima nelayan dengan asumsi data tidak cukup untuk menduga kurva permintaan pemanfaatan langsung. Harga yang langsung diterima oleh nelayan tersebut juga digunakan untuk meminimalisasi distorsi pasar. Spesies yang dihitung merupakan spesies yang menghabiskan seluruh daur hidupnya di area terumbu karang. Secara matematis, manfaat langsung tersebut dihitung dengan persamaan berikut :

$T M L=\sum_{i=1}^{n} P i . Q i$

Keterangan :

$\mathrm{TML}=$ Total manfaat langsung $/$ Total direct bennefits

$\mathrm{Pi} \quad=$ Harga ikan yang berlaku di pasar (Rp/Kg)/Market fish price

Qi = Jumlah ikan yang diekstraksi selama satu tahun $(\mathrm{Kg}) /$ The amount of extracted fish in a year

\section{B. Travel Cost Method (TCM)}

Untuk menghitung manfaat langsung tidak ekstraktif dilakukan dengan Travel Cost Method (TCM), yaitu metode yang mengkaji biaya yang dikeluarkan tiap individu untuk mendatangi tempat rekreasi Gili Sulat Gili Lawang. Prinsip yang mendasari metode ini adalah bahwa biaya yang dikeluarkan untuk berwisata ke suatu area dianggap sebagai "harga" akses area tersebut. Sedangkan untuk mengetahui surplus konsumen dari wisatawan yang datang ke kawasan konservasi Gili Sulat Gili Lawang dilakukan dengan pendekatan fungsi permintaan atas kunjungan sebagai berikut, (Adrianto, 2006):

$$
\operatorname{Ln} V_{i}=\beta_{0}+\beta_{1} \ln T C_{i}+\beta_{2} \ln J_{i}+\beta_{3} \ln A
$$

Keterangan :

$V_{i} \quad=$ Frekuensi kunjungan/ Frequency of visit

$\mathrm{TC}=$ Total biaya perjalanan/ Total travel cost

$\mathrm{J}=$ = Pekerjaan wisatawan/ Tourist jobs

A = Umur wisatawan/ Tourist age

$i \quad=1,2,3,4, \ldots \ldots \ldots . n$

$\beta=$ Nilai Parameter Regresi/ Regression parameter value 
Parameter $\beta_{0}, \beta_{1}, \beta_{2}$ dapat diestimasi menggunakan teknik regresi sederhana (Ordinary Least Square, OLS). Rata-rata surplus konsumen secara individu diestimasi dengan menggunakan persamaan (Christiensson, 2000) dalam Adrianto (2006) :

$$
C S i=-\frac{V i}{\beta i}
$$

$V_{i}$ adalah frekuensi kunjungan individu $i$ dan $\beta_{i}$ adalah nilai parameter regresi untuk biaya perjalanan (TC).

Total benefit ini dapat dilakukan untuk multi years dengan mendiskon sesuai dengan prosedur yang berlaku menggunakan tingkat diskon yang sesuai dengan karakteristik sumberdaya yang dihitung.

\section{Valuasi Biaya Konservasi}

Nilai total biaya dari kegiatan konservasi diketahui dengan penjumlahan biaya-biaya yang dikeluarkan dalam penerapan kawasan konservasi.

$$
T C=\sum_{i=1}^{4} C_{i}
$$

Keterangan :

$\mathrm{TC}=$ Total cost program konservasi / Total cost of conservation program

$\mathrm{C}_{1}$ = Biaya investasi program konservasi / Investment cost of conservation program

$\mathrm{C}_{2}=$ Biaya operasional program konservasi / Operational cost of conservation program

$\mathrm{C}_{3}=$ Biaya transaksi program konservasi / Transaction Cost Of Conservation Program

$\mathrm{C}_{4}$ = Biaya sosial program konservasi / Social cost of conservation program

Biaya investasi program konservasi dihitung dari biaya yang dikeluarkan oleh Pemerintah daerah dan Pemerintah Pusat. Menurut North \& Thomas (1973) dalam Anggraeni (2006), biaya transaksi (transaction cost) mencakup biaya pencarian (search cost) yaitu biaya untuk mendapatkan informasi pasar, biaya negoisasi (negotiation cost) yaitu biaya merundingkan syarat-syarat suatu transaksi/pertukaran (cost of negotiation the terms of the exchange), dan biaya pelaksana (enforcement costs) yaitu biaya untuk melaksanakan suatu kontrak/transaksi (cost enforcing the contract). Biaya monitoring penegakan hukum. Dalam konteks pengelolaan sumber daya alam, termasuk juga biaya pemeliharaan sumber daya alam, dan biaya monitoring penegakan hukum. Biaya sosial merupakan biaya yang timbul akibat hilangnya kesempatan masyarakat atas larangan melakukan eksploitasi sumber daya di kawasan konservasi.

\section{HASIL DAN PEMBAHASAN}

\section{Potensi KKLD Gili Sulat dan Gili Lawang}

Kawasan Konservasi Laut Daerah (KKLD) Gili Sulat dan Gili Lawang termasuk dalam wilayah administrasi Desa Sugian, Kecamatan Sambelia, Kabupaten Lombok Timur, Propinsi Nusa Tenggara Barat. Hasil interpetasi citra satelit Ikonos oleh PT. Pinter Konsultama pada tahun 2003, Gili Sulat dan Gili Lawang banyak ditutupi oleh mangrove dan semak belukar. Pulau Gili Sulat mempunyai luas 6.940.466 $\mathrm{M}^{2}(694 \mathrm{Ha})$ dengan panjang garis pantai $13.069 \mathrm{M}(13 \mathrm{Km})$ dan panjang pulau $5,16 \mathrm{Km}$ serta lebar pulau 1,88 Km. Sedangkan Luas Pulau Gili Lawang adalah 4.384.638 $\mathrm{M}^{2}$ (438 Ha) dengan panjang garis pantai $9.856 \mathrm{~m}(9,9 \mathrm{Km})$ dan panjang pulau $3,57 \mathrm{Km}$ serta lebar pulau $1,47 \mathrm{Km}$ (Tabel 1).

Dalam Peraturan Daerah Kabupaten Lombok Timur Nomor 10 Tahun 2006 tentang pengelolaan Kawasan Konservasi Laut Daerah disebutkan bahwa KKLD di Kabupaten Lombok Timur meliputi Daerah Perlindungan Laut (DPL) Gili Sulat-Gili Lawang, DPL Gili Petagon, Suaka Perikanan Gusoh Sandak, Suaka Perikanan Gili Rango, Suaka Perikanan Sapak Kokok, Suaka Perikanan Taked Pedamekan dan Suaka Perikanan 
Tabel 1. Tutupan Penggunaan Lahan Pulau Gili Sulat dan Gili Lawang, Lombok Timur, Nusa Tenggara Barat, 2002

Table 1. Lands Used Coverage of Gili Sulat and Gili Lawang Islands, East Lombok, West Nusa Tenggara, 2002

\begin{tabular}{llrrr}
\hline & $\begin{array}{l}\text { Tipe Penggunaan Lahan/ } \\
\text { Types of land use }\end{array}$ & $\begin{array}{c}\text { Gil Sulat } \\
\text { (ha) }\end{array}$ & Gili Lawang (ha) & $\begin{array}{c}\text { Jumlah/ } \\
\text { Aggregate(ha) }\end{array}$ \\
\hline 1. & Belukar/Scrub & 2,409 & 21,367 & 23,776 \\
2. & Karang Penghalang/ Barrier reef & 2,236 & 5,996 & 8,232 \\
3. & Laguna/Lagoon & - & 13,028 & 13,028 \\
4. & Mangrove/Mangrove & 641,630 & 369,023 & $1.010,653$ \\
5. & Padang Lamun/ Seagrass & 47,599 & 35,682 & 83,281 \\
6. & Pasir/Sand & 0,775 & 1,932 & 2,707 \\
7. & Rataan Terumbu & 178,688 & 181,254 & 359,942 \\
& Karang/Coral reef & & & \\
8. & Tanah Terbuka/ Open land & 35,666 & 40,892 & 76,558 \\
& $\quad$ Total & $\mathbf{9 0 9 , 0 0 3}$ & $\mathbf{6 6 9 , 1 7 4}$ & $\mathbf{1 . 5 7 8 , 1 7 7}$ \\
\hline
\end{tabular}

Sumber : Hasil studi identifikasi KKLD Lombok Timur, 2002/

Source : Result of identification study for KKLD Lombok Timur, 2002

Taked Belanting. DPL Gili Sulat-Gili Lawang mempunyai luas 1.206 ha meliputi zona inti I di Gili Lawang, zona inti II di Gili Sulat, dan zona penyangga. (Gambar 1)
Sesuai dengan ketentuan Peraturan Pemerintah Republik Indonesia tentang Konservasi Pasal 24 yang menjelaskan bahwa (1) Pengelolaan kawasan konservasi perairan

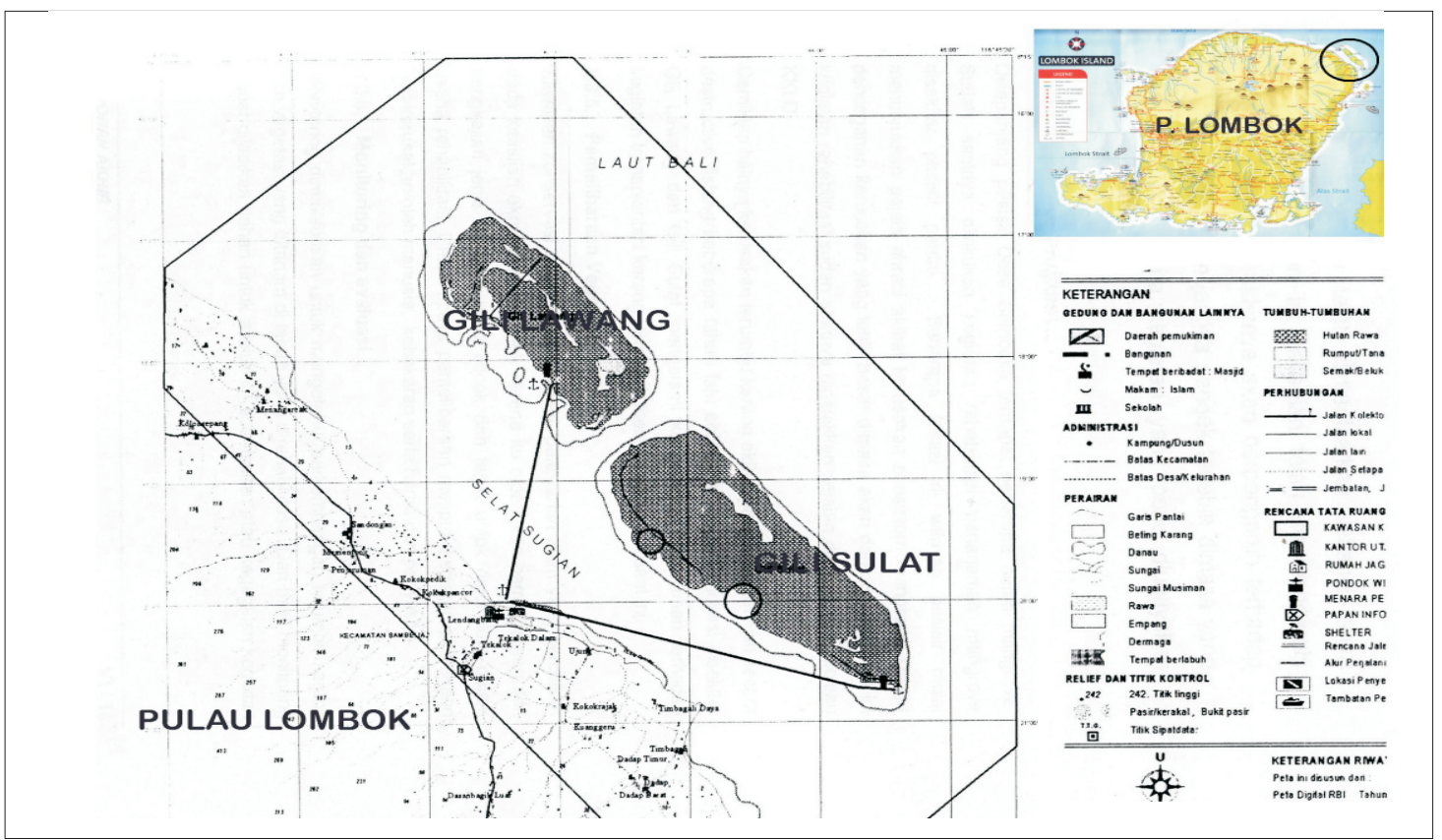

Gambar 1. Peta Lokasi KKLD Gili Sulat dan Gili Lawang, Lombok Timur, Nusa Tenggara Barat, 2003

Figure 1. Map of "KKLD” Gili Sulat and Gili Lawang, East Lombok, West Nusa Tenggara, 2003 
dilakukan berdasarkan sistem zonasi; (2) Sistem Zonasi Kawasan Konservasi Perairan.

Perairan sebagaimana dimaksud pada ayat (1) terdiri dari zona inti, zona perikanan berkelanjutan, zona pemanfaatan dan zona lainnya sesuai karakteristik geografis, potensi ekologis dan kondisi nilai habitatnya.

Peraturan-peraturan yang spesifik diberlakukan pada setiap zona. Kawasan terluar dari KKLD adalah zona pemanfaatan. Peran zona pemanfaatan adalah sebagai penyaring dampak kegiatan-kegiatan di luar kawasan sehingga mampu mengurangi pengaruh dari luar terhadap potensi dalam KKLD. Zona inti disepakati berdasarkan pengetahuan empiris masyarakat setempat mengenai lokasi pemijahan biota-biota laut dan pesisir ekonomis, antara lain berupa habitat pesisir dan laut terpadu (hutan bakau, padang lamun, dan terumbu).

Mengingat dinamika proses ekologi, maka potensi masing-masing zona dapat mengalami perubahan. Sehingga memerlukan peninjauan, penilaian kembali, serta pengubahan peruntukannya. Demi menjamin keberlanjutan pengelolaan, pemeliharaan dan pengamanan potensi kawasan, setiap perubahan dan penentuan zonasi harus melibatkan pihak-pihak terkait dan berkepentingan dengan potensi KKLD Gili Sulat dan Gili Lawang. Adanya keterlibatan ini memberi peluang bagi pihak-pihak tersebut untuk mengatur sendiri dalam wilayah kegiatan masing-masing yang dikoordinasikan dengan Pengelola KKLD Gili Sulat dan Gili Lawang. Pada sisi lain, keterlibatan masyarakat dalam setiap kegiatan pemeliharaan dan pengawasan KKLD diharapkan mendorong rasa kepemilikan terhadap keberadaan KKLD Gili Sulat dan Gili Lawang.

\section{Pemanfaatan dan Pendayagunaan KKLD Gili Sulat dan Gili Lawang}

KKLD Gili Sulat dan Gili Lawang terdiri dari mangrove, padang lamun dan terumbu karang. Keberadaan KKLD Gili Sulat-Gili
Lawang memberikan manfaat yang dapat dikelompokkan menjadi manfaat langsung ekstraktif perikanan, manfaat langsung non ekstraktif (pariwisata), manfaat sebagai penghalang dan manfaat nilai estetika dan keanekaragaman hayati. Ekosistem mangrove yang ada dimanfaatkan oleh ikanikan pelagis sebagai tempat pemijahan dan asuhan (nursery ground). Hal ini dibuktikan dengan ditemukannya benih-benih ikan pelagis perairan yang terdapat dalam ekosistem mangrove sedangkan ekosistem terumbu karang merupakan tempat pemijahan bagi ikan-ikan jenis karang, sementara laguna umumnya dimanfaatkan oleh ikan-ikan karang yang masih berukuran kecil (stadia benih) sebagai daerah asuhan. Adapun padang lamun merupakan ekosistem yang dimanfaatkan sebagai daerah mencari makan (feeding ground).

Ikan-ikan demersal dewasa akan bermigrasi keluar dari ekosistem terumbu karang atau padang lamun dan mencari makan pada perairan yang berarus, yang banyak ditemukan di selat antara Pulau Gili Sulat dan Gili Lawang. Migrasi yang dilakukan ikan demersal termasuk ikan-ikan karang adalah migrasi pendek dalam wilayah yang sempit. Sementara migrasi ikan-ikan pelagis merupakan migrasi panjang keluar dari wilayah ekosistem mangrove menuju perairan lepas.

\section{Penangkapan dan Budidaya Ikan}

Masyarakat yang berada di sekitar lokasi KKLD Gili Sulat dan Gili Lawang dapat memanfaatkan kawasan di luar zona inti dengan melakukan penangkapan ikan yang merupakan hasil migrasi ikan dewasa, budidaya ikan, dan pariwisata. Penangkapan ikan masih dapat dilakukan oleh nelayan di KKLD dan juga kawasan sekitarnya karena zona inti yang benar-benar dilarang melakukan penangkapan hanya seluas 5 ha. Luasan ini merupakan luasan zona inti yang telah disepakati oleh pengelola KKLD dengan nelayan. Walaupun dalam SK Bupati zona inti untuk KKLD ini jauh lebih luas daripada $5 \mathrm{Ha}$ tersebut. Lokasi $5 \mathrm{Ha}$ tersebut dipilih atau 
ditetapkan sebagai zona inti, karena kawasan tersebut mempunyai terumbu karang yang lebih baik dibandingkan lokasi lainnya.

Nelayan yang melakukan penangkapan di sekitar KKLD, terdiri dari nelayan yang berasal dari Desa Sugian dan beberapa nelayan yang berasal dari Labuhan Lombok, Pulau Sumbawa, Pulau Bima, Pulau-pulau lainnya disekitar Pulau Lombok. Nelayan melakukan penangkapan dengan armada kapal motor, motor tempel dan perahu tanpa motor. Alat tangkap yang dioperasikan oleh nelayan terdiri dari jala (cast net), jaring insang (gill net), pancing (hook and line), rawai mini (mini longline), panah (harpoon). Jenis ikan yang banyak didaratkan terdiri dari kerapu macan (Epinephelus yuscoguttatus), kakap merah (Lutjanus campechanuus), tongkol (Auxis thazard), kuwe (caranx sexfasciatus), kembung (Castrelliger spp), tembang (Clupea sp), layang (Decapterus kuroides) serta beberapa jenis ikan lainnya.

Selain aktivitas perikanan tangkap, di zona pemanfaatan KKLD Gili Sulat-Gili Lawang juga terdapat budidaya perikanan. Kegiatan budidaya dilakukan sebagai salah satu mata pencaharian alternatif untuk mengurangi ketergantungan masyarakat terhadap hasil penangkapan ikan. Kegiatan budidaya dipelopori oleh pemerintah dengan menerapkan budidaya lobster dan rumput laut. Kegiatan budidaya diserahkan kepada masyarakat melalui kelompok yang dibentuk oleh masyarakat di masing-masing dusun. Di Susun Dadap budidaya udang lobster (shrimp lobster) dilakukan sebanyak satu (1) unit dan budidaya rumput laut dilakukan sebanyak 4 unit yang dikelola oleh dua (2) kelompok masyarakat.

\section{Aktivitas dan Kelembagaan Pariwisata}

Aktivitas wisata yang dilakukan di sekitar KKLD adalah diving, snorkeling, pemancingan, wisata terumbu karang, wisata mangrove dan wisata burung. Pengunjung yang banyak adalah pengunjung dengan tujuan untuk melakukan pemancingan ikan.
Pengunjung dengan tujuan pemancingan umumnya berasal dari wilayah yang tidak jauh dari Desa Sugian seperti Labuhan Pandan, Masbagik, Selong serta beberapa daerah lainnya di Kabupaten Lombok Timur. Wisata memancing ini dilakukan dengan cara menyewa perahu nelayan yang Dusun Dasan Baru atau menyewa perahu nelayan yang sedang tidak melakukan penangkapan seperti di Dusun Ujung dan Dadap. Wisatawan juga ada yang dengan langsung berjalan di air ke lokasi pemancingan yang tidak jauh dari pantai.

Wisata selam (diving) dan snorkeling umumnya dilakukan oleh wisatawan dari mancanegara. Lokasi diving dan snorkeling terdapat di sekitar selat antara Gili Sulat dan Gili Lawang. Wisata terumbu karang, mangrove dan burung umumnya dilakukan oleh orang-orang yang mengembangkan ilmu pengetahuan seperti siswa, mahasiswa, peneliti, perekayasa serta beberapa bidang ilmu dan pengetahuan lainnya. Wisatawan yang telah banyak berkunjung terdiri dari mahasiswa dan peneliti.

Pariwisata yang dikembangkan adalah pariwisata berbasis masyarakat, untuk pengelolaannya banyak melibatkan masyarakat. Penginapan untuk wisatawan yang telah disiapkan oleh pengelola berupa homestay yang memungkinkan wisatawan untuk berbaur dan tinggal bersama masyarakat. Fasilitas yang disediakan adalah kamar-kamar yang cukup nyaman dilengkapi dengan tempat tidur dan masih berada dalam satu rumah dengan pemiliknya. Homestay yang sudah ada dikelola kelompok masyarakat Dusun Dasan Baru dan dipromosikan dengan nama Koko Pedek Homestay. Selain itu juga terdapat rumah tamu di kantor pengelolaan KKLD di Dusun Tekalok.

\section{Nilai Ekonomi Manfaat Langsung dan Tidak Langsung}

Nilai ekonomi manfaat langsung dari penangkapan ikan yang dilakukan di sekitar 
KKLD diketahui dari jumlah ikan yang didaratkan dikalikan dengan rata-rata harga. Jumlah ikan yang didaratkan di Desa Sugian diperoleh dari data sekunder Dinas Kelautan dan Perikanan Kabupaten Lombok Timur. Jumlah produksi ikan di Desa Sugian pada tahun 2008 adalah 473,3 ton. Variabel harga yang digunakan didalam penelitian ini adalah rata-rata harga dari seluruh responden yaitu Rp. 10.253 per kg. Dengan demikian dapat diketahui, manfaat langsung dari penangkapan ikan yang dilakukan di sekitar KKLD adalah Rp. 4,8 milyar per tahun.

Manfaat langsung non ekstraktif dari adanya KKLD adalah manfaat dari kegiatan pariwisata. Pariwisata di KKLD Gili Sulat dan Gili Lawang boleh dikatakan dalam tahap permulaan dan masih sangat diperlukan adanya promosi supaya lokasi ini dikenal oleh masyarakat luas. banyaknya jumlah kunjungan yang dipengaruhi oleh total biaya, pekerjaan, umur dan daerah asal.

Fungsi permintaan pariwisata dibangun melalui persamaan eksponensial yang kemudian dapat diubah menjadi analisis regresi sederhana dengan menggunakan nilai In dari masing-masing data. Nilai R-squared yang diperoleh cukup bagus yaitu $86 \%$. Nilai ini dapat diterjemahkan bahwa jumlah kunjungan wisatawan per tahun dapat dijelaskan oleh biaya perjalanan, jenis pekerjaan, umur dan daerah asal sebesar $86 \%$, dan sisanya dijelaskan oleh variabel lain diluar model. Koefisien biaya berpengaruh negatif terhadap jumlah kunjungan. Semakin tinggi biaya yang dikeluarkan, semakin sedikit jumlah kunjungan yang dilakukan. Koefisien masing-masing variabel dapat dilihat pada Tabel 2.

\section{Tabel 2. Koefisien Regresi Kurva Permintaan Pariwisata di KKLD Gili Sulat dan Gili Lawang, Nusa Tenggara Barat, 2009}

Table 2. Regression Coefficient of Tourism Demand Curve in KKLD Gili Sulat and Gili Lawang, West Nusa Tenggara, 2009

\begin{tabular}{lrr}
\hline \multicolumn{1}{c}{ Uraian/Description } & Koefisien/Coefficient & P-Value \\
\hline Intersep/Intercept & 8.107165 & 0,00356 \\
Pengeluaran/Expenditure & $-0,95621$ & 0,00000 \\
Pekerjaan/Job & $-0,81291$ & 0,14075 \\
Umur/Age & 1,471427 & 0,02661 \\
Daerah asal/Home lands & 0,412675 & 0,14924 \\
$\mathrm{R}^{2}$ & 0,864476 & \\
\hline
\end{tabular}

Sumber : Data diolah, 2009/Source : Data processed, 2009

Pengunjung yang datang masih didominasi oleh masyarakat di sekitar Lombok Timur dan beberapa orang yang mempunyai hobi memancing. Pada saat penelitian ini dilakukan hanya dapat ditemui para pemancing yang akan menyalurkan hobinya dan menghabiskan waktu di akhir pekan. Manfaat dari adanya kegiatan pariwisata diketahui dengan membangun kurva permintaan untuk memperoleh surplus konsumen. Kurva permintaan dibangun dari
Dari Tabel 2 dapat diketahui bahwa kurva permintaan mempunyai kemiringan negatif yang dapat dilihat dari nilai koefisien pengeluaran yang bertanda negatif. Variabel pengeluaran dan umur berpengaruh signifikan pada selang kepercayaan $90 \%$ terhadap penentuan jumlah kunjungan. Untuk dapat menggambarkan kurva permintaan dengan terlebih dahulu mengembalikan ke bentuk persamaan asal $V=\beta_{0} * C^{\beta_{1}}$ Fungsi permintaan yang diperoleh adalah $V=731096 C^{-0,96} \mathrm{Jumlah}$ 
kesediaan membayar dari masing-masing pengunjung terhadap suatu objek wisata diketahui dari total biaya yang dikeluarkan. Kurva permintaan dapat digambarkan dengan mentransformasi persamaan diatas kedalam bentuk fungsi $\mathrm{V}$ (jumlah kunjungan), maka fungsi permintaannya adalah:

$$
C=13568047 V^{-1,05}
$$

Total kesediaan membayar juga dapat diketahui dengan rata-rata jumlah kunjungan sebanyak 9 kali dalam setahun. Total kesediaan membayar dapat dituliskan sebagai berikut:

$$
\begin{aligned}
U & =\int_{0}^{a} f(V) d V \\
U & =\int_{0}^{0} 135680^{9} 47 V^{-1,05} \\
& =2.849 .002
\end{aligned}
$$

Besaran surplus konsumen dapat dihitung dengan cara mengurangkan total kesediaan membayar dengan total biaya atau sejumlah uang yang benar-benar dikeluarkan. Surplus konsumen dari kegiatan pariwisata di
KKLD Gili Sulat dan Gili Lawang adalah Rp. 1.622.699 per individu selama satu tahun. Sedangkan total manfaat dari kegiatan pariwisata dapat diketahui dengan mengalikan surplus konsumen individu dengan total jumlah pengunjung dalam satu tahun. Jumlah rata-rata pengunjung di seluruh lokasi pantai yang meliputi Koko Pedek, Tekalok dan Dadap dalam satu tahun terdapat 2.500 pengunjung. Hasil perhitungan menunjukan total manfaat dari kegiatan pariwisata adalah Rp. 4.056.672.500.

Manfaat KKLD Gili Sulat dan Gili Lawang yang memiliki beberapa jenis sumber daya, tidak hanya dari usaha penangkapan ikan dan kegiatan pariwisata. Terumbu karang yangberada di KKLD mempunyai manfaat untuk memberikan perlindungan terhadap pantai supaya tidak terjadi abrasi atau erosi dan juga memiliki nilai estetika dan keanekaragaman hayati. Menurut Cesar (1997) potensi keuntungan bersih per tahun dari terumbu karang yang sehat untuk perlindungan pantai adalah US $\$ 5.500$ per $\mathrm{Km}^{2}$. Pada KKLD Gili Sulat dan Gili Lawang terdapat tutupan Iahan oleh karang

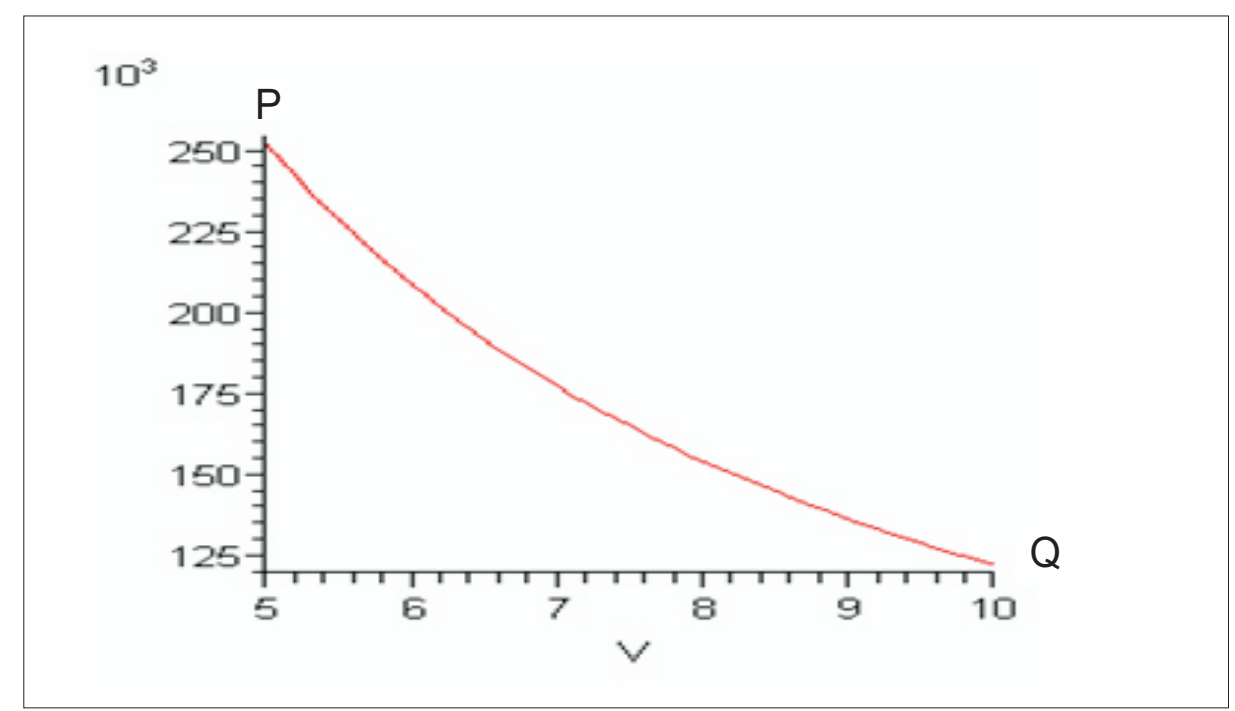

Gambar 2. Kurva Konsumen Surplus Kegiatan Pariwisata di KKLD Gili Sulat dan Gili Lawang, Lombok Timur, Nusa Tenggara Barat, 2009

Figure 2. Consumer Surplus Curve of Tourism Activity in KKLD Gili Sulat and Gili Lawang, East Lombok, West Nusa Tenggara, 2009 
penghalang seluas $0,0823 \mathrm{~km}^{2}$. Total keuntungan bersih dari terumbu karang untuk perlindungan pantai adalah Rp. 4.073.850 dengan menggunakan nilai tukar Rp. 9.000,perUS\$.

Potensi keuntungan dari nilai estetika dan keanekaragaman hayati ekosistem terumbu karang adalah US\$2.400 per $\mathrm{Km}^{2}$ per tahun (Caesar, 1997). Rataan terumbu karang di KKLD Gili Sulat dan Gili Lawang adalah $3,599 \mathrm{Km}^{2}$. Total keuntungan bersih dari terumbu karang untuk nilai estetika dan keanekaraman hayati adalah Rp. 77.738.400 dengan nilai tukar Rp. 9.000 per US\$. Manfaat yang dapat diidentifikasi dan di hitung dalam penelitian ini dapat dilihat pada Tabel 3 . dan transparan. Pendekatan pengelolaan didasarkan pada efisien, efektif dan dinamis. Dalam rangka mewujudkan pengelolaan yang efisien dan efektif telah dilakukan koordinasi pengawasan KKLD bersama dengan Komite Perlindungan dan Pengawasan Laut (KPPL) Kecamatan Sambelia. Selain itu terdapat dukungan Lembaga Swadaya Masyarakat (LSM) yang peduli lingkungan, yaitu Komunitas Dua Pulau yang gencar melakukan sosialisasi tentang pentingnya KKLD, baik secara langsung maupun media elektronik (radio lokal).

Pengelolaan KKLD Gili Sulat dan Gili Lawang telah didukung oleh beberapa instrumen kebijakan. Salah satu instrumen kebijakan pengelolaan tersebut diatur dalam

Tabel 3. Pemanfaatan KKLD Gili Sulat dan Gili Lawang, Lombok Timur, Nusa Tenggara Barat, 2009

Table 3. Utilization of "KKLD" Gili Sulat and Gili Lawang, East Lombok, West Nusa Tenggara,

\begin{tabular}{clc}
\hline No. & Jenis manfaat/ Types of utilization & $\begin{array}{c}\text { Nilai/ Value (Rp.000/th)/ } \\
\text { (Rp.000/year) }\end{array}$ \\
\hline 1 & Perikanan/Fisheries & $4.852 .744,00$ \\
2 & Pariwisata/Tourism & $4.056 .672,00$ \\
3 & Perlindungan pantai/Coastal protection & $4.073,85$ \\
4 & Nilai estetika dan keanekaragaman hayati/ & $77.738,40$ \\
& Aesthetic values and biodiversity & $\mathbf{8 . 9 9 1 . 2 2 8 , 2 5}$ \\
& Jumlah/Aggregate & $\mathbf{8}$
\end{tabular}

Sumber : Data diolah, 2009/Source : Data processed, 2009

Tabel 3 menunjukkan bahwa manfaat terbesar diperoleh dari nilai perikanan. Total manfaat KKLD Gili Sulat dan Gili Lawang adalah Rp 8,991 milyar per tahun. Nilai ini dapat lebih tinggi lagi jika nilai estetika dan keanekaragaman hayati yang terdapat di hutan mangrove dapat diketahui.

\section{Pengelolaan KKLD Gili Sulat dan Gili Lawang}

KKLD Gili Sulat dan Gili Lawang dikelola oleh Badan Pengelola Kawasan Konservasi Laut Daerah Lombok Timur (BP-KKLD) yang telah dibentuk oleh pemerintah daerah. Prinsip pengelolaannya bersifat terpadu, partisipatif
Peraturan Daerah Nomor188.45/452/KP/ 2004 tentang Pengelolaan KKLD Lombok Timur ini mengatur tentang penetapan KKLD Gili Sulat dan Gili Lawang, zona inti, zona pemanfaatan, tata ruang dan Badan pengelola KKLD. Peraturan Daerah yang lain terkait dengan pengelolaan KKLD Gili Sulat dan Gili Lawang adalah (1) Peraturan Daerah Kabupaten Lombok Timur Nomor 9 Tahun 2006 tentang Pengelolaan Sumber Daya Perikanan Pantai Secara Partisipatif. Kemudian adalah Peraturan Daerah Kabupaten Lombok Timur Nomor 10 Tahun 2006 tentang Pengelolaan Kawasan Konservasi Laut Daerah (ii) Peraturan Daerah 
Kabupaten Lombok Timur Nomor 13 Tahun 2006 tentang Pedoman Pengelolaan Sumber Daya Hutan Berbasis Masyarakat.

Hambatan yang selama ini dialami dalam pengelolaan KKLD Gili Sulat dan Gili Lawang adalah kurangnya pengawasan yang disebabkan oleh minimnya dana untuk melakukan pengawasan. Biaya operasional dalam melakukan pengawasan hanya mengandalkan hasil penyisihan pendapatan yang diperoleh dari penyewaan fasilitas milik kantor KKLD. Minimnya pengawasan oleh KPPL atau pihak KKLD maka informasi dari nelayan menjadi lebih banyak diandalkan dengan konsekuensi informasi yang diperoleh seringkali terlambat atau tidak bisa ditindaklanjuti dengan cepat untuk mencegah atau meminimalkan terjadinya pelanggaran di KKLD.

Unsur penting dalam pengelolaan KKLD selain dukungan kebijakan adalah biaya pengelolaan. Biaya yang dikeluarkan dalam pengelolaan KKLD dapat dibedakan menjadi biaya investasi, biaya operasional dan biaya lainnya seperti biaya transaksi dan biaya sosial. Biaya investasi adalah biaya yang dikeluarkan meliputi biaya untuk penentuan atau penetapan sebagai kawasan konservasi dan biaya pembangunan sarana dan prasarana pengelolaan. Biaya-biaya ini ditanggung oleh pemerintah pusat melalui Kementerian Kelautan dan Perikanan dan pemerintah daerah Kabupaten Lombok Timur.

Biaya investasi yang dikeluarkan dalam rangka pengelolaan dan pengawasan KKLD mencapai Rp.2.230.751.000. Biaya investasi yang dikeluarkan pada tahun 2006 berasal dari APBN kecuali untuk pengadaan tanah dan demplot lobster serta rumput laut yang bersumber dari APBD Kabupaten Lombok Timur. Sedangkan biaya operasional yang diperlukan dalam rangka pengelolaan dan pengawasan KKLD Gili Sulat dan Gili Lawang Kabupaten Lombok Timur sebesar Rp. 30.760.000 per tahun yang dibebankan pada APBD Kabupaten Lombok Timur. Rincian biaya pengelolaan KKLD Gili Sulat dan Gili Lawang dapat dilihat pada Tabel 4.

\section{Strategi Pengelolaan KKLD Gili Sulat dan Gili Lawang}

Keberhasilan pengelolaan KKLD dipengaruhi oleh partisipasi masyarakat sekitar KKLD. Selama masyarakat setempat masih dianggap obyek pengelolaan maka akan sulit terjamin kerjasama, koordinasi dan komunikasi yang diharapkan. Hal ini karena masyarakat sekitar menggantungkan sebagian atau seluruh hidupnya pada sumber daya alam yang ada di sekitar KKLD. Oleh karena itu koordinasi antara pengelola KKLD, LSM dan masyarakat harus senantiasa ditingkatkan sehingga pemantauan dan pengawasan KKLD dapat berlangsung efektif dan efisien.

Dalam rangka mencapai hasil yang optimal dalam pengelolaan KKLD Gili Sulat dan Gili Lawang maka diperlukan sebuah sistem pengelolaan yang efektif dan efisien. Beberapa hal yang perlu dipertimbangkan dalam rangka optimalisasi KKLD Gili Sulat-Gili Lawang diantaranya adalah :

\section{a. Manajemen data dan informasi}

Data merupakan modal dasar yang harus dimiliki dalam pengelolaan KKLD. Keberadaan data yang akurat dan tepat waktu akan memudahkan monitoring dan evaluasi keberhasilan program yang dilaksanakan. Data mengenai kualitas sumber daya yang ada, jumlah pelaku yang terkait dengan KKLD, perkembangan kuantitas sumber daya perikanan dan data terkait lainnya akan memudahkan langkah dalam pengelolaan KKLD. Selain itu, perkembangan informasi baik dari masyarakat maupun institusi pemerintah harus selalu diikuti perkembangannya.

\section{b. Pengelolaan batas dan zonasi}

Penentuan batas dan zonasi merupakan faktor penting yang berpengaruh terhadap keberhasilan KKLD. Penentuan zonasi yang tepat dan dihasilkan dari kesepakatan 
Tabel 4. Biaya Pengelolaan KKLD Gili Sulat dan Gili Lawang, Lombok Timur, Nusa Tenggara Barat, 2009

Table 4. Management Cost of "KKLD" Gili Sulat and Gili Lawang, East Lombok, West Nusa Tenggara, 2009

\begin{tabular}{|c|c|c|c|c|}
\hline $\begin{array}{l}\text { Komponen Biaya/ } \\
\text { Cost component }\end{array}$ & $\underset{\text { Satuan } /}{\text { Unit }}$ & $\begin{array}{l}\text { Volumel } \\
\text { Volume }\end{array}$ & $\begin{array}{c}\text { Nilai per } \\
\text { satuan/Value } \\
\text { per unit }\end{array}$ & $\begin{array}{l}\text { Jumlah/ } \\
\text { Aggregate }\end{array}$ \\
\hline $\begin{array}{l}\text { Biaya Investasi/ } \\
\text { Cost Investment }\end{array}$ & & & & 2.230 .751 .000 \\
\hline $\begin{array}{l}\text { Biaya penelitian/Research } \\
\text { cost }\end{array}$ & $\begin{array}{l}\text { Paket/ } \\
\text { Package }\end{array}$ & 3 & 300.000 .000 & 900.000 .000 \\
\hline Tanah/Lands & Are/Are & 90 & 2.200 .000 & 200.000 .000 \\
\hline Gedung kantor/Office room & Unit/Unit & 1 & 97.299 .000 & 97.299 .000 \\
\hline Rumah tamu/Guest house & Unit/Unit & 3 & 102.359 .000 & 307.077 .000 \\
\hline $\begin{array}{l}\text { Peralatan Kantor/Office } \\
\text { equipment }\end{array}$ & Set/Set & 1 & 49.650 .000 & 49.650 .000 \\
\hline Rumah jaga/Guard house & Unit/Unit & 2 & 22.375 .000 & 44.750 .000 \\
\hline $\begin{array}{l}\text { Jembatan untuk wisata } \\
\text { mangrove/Mangrove tourism } \\
\text { bridge }\end{array}$ & $\begin{array}{l}\text { Paket/ } \\
\text { Package }\end{array}$ & 1 & 29.749 .000 & 29.749 .000 \\
\hline Kantor KPPL/KPPL office & Unit/Unit & 1 & 46.750 .000 & 46.750 .000 \\
\hline Saung/Shelter & Unit/Unit & 6 & 7.454 .000 & 44.724 .000 \\
\hline Kapal patroli/Patrol boat & Unit/Unit & 1 & 149.353 .000 & 149.353 .000 \\
\hline $\begin{array}{l}\text { Pelampung dan } \\
\text { perlengkapan untuk } \\
\text { menyelam/Diving equipment }\end{array}$ & Set/Set & 5 & 11.800 .000 & 59.400 .000 \\
\hline $\begin{array}{l}\text { Tower dan Pintu } \\
\text { gerbang/Water tank and gate }\end{array}$ & $\begin{array}{l}\text { Paket/ } \\
\text { Package }\end{array}$ & 1 & 48.961 .000 & 48.961 .000 \\
\hline Dermaga/Jetty & $\begin{array}{l}\text { Paket/ } \\
\text { Package }\end{array}$ & 3 & 46.779 .333 & 140.338 .000 \\
\hline $\begin{array}{l}\text { Papan Informasi/Board } \\
\text { information }\end{array}$ & $\begin{array}{l}\text { Paket/ } \\
\text { Package }\end{array}$ & 1 & 112.700 .000 & 112.700 .000 \\
\hline $\begin{array}{l}\text { Biaya } \\
\text { Transaksi/Transaction cost }\end{array}$ & & & & 34.000 .000 \\
\hline $\begin{array}{l}\text { Demplot lobster/Lobster } \\
\text { project }\end{array}$ & Unit/Unit & 1 & 24.000 .000 & 24.000 .000 \\
\hline $\begin{array}{l}\text { Demplot rumput } \\
\text { laut/Seaweed project }\end{array}$ & Unit/Unit & 4 & 2.500 .000 & 10.000 .000 \\
\hline $\begin{array}{l}\text { Biaya Operasional/ } \\
\text { Operational Cost }\end{array}$ & & & & 30.760 .000 \\
\hline $\begin{array}{l}\text { Gaji pegawai/Employees } \\
\text { salary }\end{array}$ & $\begin{array}{l}\text { Bulan/ } \\
\text { Month }\end{array}$ & 12 & 2.300 .000 & 27.600 .000 \\
\hline $\begin{array}{l}\text { Biaya pengawasan/ } \\
\text { Surveillance cost }\end{array}$ & $\begin{array}{l}\text { Bulan/ } \\
\text { Month }\end{array}$ & 12 & 100.000 & 1.200 .000 \\
\hline $\begin{array}{l}\text { Perawatan kantor/Office } \\
\text { maintenance }\end{array}$ & $\begin{array}{l}\text { Tahun/ } \\
\text { Year }\end{array}$ & 1 & 1.000 .000 & 1.000 .000 \\
\hline Rekening listrik/Electric bill & $\begin{array}{l}\text { Bulan/ } \\
\text { Month }\end{array}$ & 12 & 80.000 & 960.000 \\
\hline
\end{tabular}

Sumber : Data diolah, 2009/Source : Data processed, 2009 
bersama antara masyarakat, akademisi dan pemerintah akan memberikan hasil sesuai dengan konsep dibuatnya kawasan konservasi dan menumbuhkan rasa memiliki pada pihak terkait (khususnya masyarakat sekitar), sehingga tumbuh kesadaran untuk ikut menjaga karena merasakan manfaat yang diperoleh dari KKLD tersebut.

\section{c. Pengelolaan sumber daya hayati dan perikanan}

Sumber daya hayati dan perikanan harus dikelola dengan baik agar kelestariannya dapat tercapai. Pemanfaatan sumber daya hayati dan perikanan harus senantiasa diawasi sehingga terdapat jaminan bahwa setiap aktivitas yang dilakukan semua pihak selalu ramah lingkungan. Pembuatan aturan operasional dalam pengelolaan sumber daya hayati dan perikanan bisa menjadi instrumen dalam memastikan kelestarian sumber daya hayati dan perikanan dapat tercapai.

\section{d. Pengelolaan sarana dan prasarana}

Sarana dan prasarana yang ada dalam rangka pengelolaan KKLD harus mendapatkan perhatian dalam pemeliharaannya. Kesadaran dan rasa tanggung jawab semua elemen masyarakat harus senantiasa dibangun sehingga timbul rasa memiliki dan membutuhkan sarana prasarana yang ada.

e. Pengelolaan pariwisata, pendidikan dan penelitian

Salah satu manfaat yang dapat dinikmati dengan adanya KKLD adalah pariwisata. Masyarakat dapat menjual keindahan sumber daya yang ada kepada wisatawan. Usaha pengembangan pariwisata secara tidak langsung akan memberikan manfaat kepada masyarakat yaitu dengan adanya tambahan pemasukan dari usaha yang dapat dihasilkan dengan adanya kegiatan pariwisata.

\section{f. Pengendalian, monitoring dan pengawasan \\ Efektifitas tujuan pengelolaan KKLD Gili Sulat dan Gili Lawang dapat dicapai dengan}

cara melakukan pengendalian agar tidak terjadi pelanggaran oleh masyarakat. Pengendalian dapat dilakukan dengan membina kerjasama dan melibatkan masyarakat dalam setiap kegiatan yang dilaksanakan pengelola. Disamping rajin melakukan pengendalian juga harus ditunjang dengan monitoring dan pengawasan yang rutin.

g. Pemberdayaan masyarakat

Dalam roadmap yang disampaikan oleh pengurus Komunitas dua (2) Pulau (K2P) disebutkan bahwa Dusun Dadap akan diarahkan untuk kegiatan perikanan budidaya, Dusun Tekalok untuk perikanan tangkap dan pusat kerajinan souvenir sedangkan Dusun Dasan Baru untuk kawasan wisata. Bersamaan dengan survai, KPPL tengah melakukan sosialisasi budidaya rumput laut untuk masyarakat Dusun Dadap. Sebelumnya di dusun tersebut sudah terdapat Keramba Jaring Apung Lobster (usaha pembesaran) dan Budidaya tiram.

Program pemberdayaan masyarakat tersebut diharapkan memberikan alternatif mata pencaharian masyarakat sekitar KKLD sehingga kebutuhan ekonomi mereka dapat terpenuhi. Adanya alternatif sumber perekonomian yang mencukupi diharapkan mampu mengurangi ketergantungan masyarakat sekitar terhadap eksploitasi sumber daya perikanan. Sehingga secara tidak langsung akan menimbulkan rasa kesadaran betapa pentingnya menjaga sumber daya perikanan yang ada.

\section{h. Penyadaran masyarakat}

Sosialisasi yang rutin baik secara langsung maupun melalui media elektronik merupakan instrumen yang ampuh dalam membangun kesadaran masyarakat terhadap pentingnya KKLD. Pihak pengelola dan LSM terkait harus sering berkoordinasi dengan masyarakat sekitar dan melibatkan masyarakat dalam pengelolaan KKLD.

I. Penguatan kapasitas kelembagaan dan sumber daya manusia 
Kelembagaan pengelolaan merupakan salah satu unsur yang penting dalam mewujudkan keberhasilan KKLD. Kelembagaan yang ada harus mampu membuka koordinasi dengan pihak terkait, termasuk didalamnya adalah perguruan tinggi, pengusaha dan LSM.

Kelembagaan yang sudah ada baik terkait langsung atau tidak langsung dengan Kawasan Konservasi Laut Daerah Gili Sulat dan Gili Lawang diantaranya adalah KPPL (Komite Pengelola Perikanan Laut), Komunitas 2 Pulau (K2P), Kelompok Wisata Homestay di Kokokpedek, Komunitas Ibu-ibu Bakul dan beberapa kelompok nelayan berdasarkan alat tangkap. Kelembagaan yang ada tersebut mempunyai peran yang berbeda, diantaranya adalah sebagai pengawas KKLD, pemberdayaan masyarakat, wadah interaksi sosial, kerjasama ekonomi, perlindungan lingkungan dan sebagainya.

j. Pengembangan jaringan kerjasama dan kemitraan

Pemberdayaan semua elemen masyarakat dalam pengelolaan KKLD Gili Sulat dan Gili Lawang akan lebih maksimal dengan adanya kerjasama dan kemitraan antara pemerintah, lembaga swadaya masyarakat, swasta, akademisi dan masyarakat. Kerjasama yang dapat dilakukan diantaranya adalah kemitraan usaha, pendampingan dan penyuluhan usaha alternatif, pengawasan kawasan konservasi dan pelatihan manajemen pengelolaan kelembagaan dan usaha.

k. Sosialisasi dan penegakan hukum yang tegas

Informasi tentang ketentuan yang berlaku pada kawasan konservasi harus disosialisasikan kepada seluruh pihak terkait, terutama kepada masyarakat yang berhubungan langsung dengan pemanfaatan sumber daya perikanan di sekitar KKLD Gili Sulat dan Gili Lawang. Ketegasan penegakan hukum bagi siapa saja yang melanggar ketentuan akan mendorong semua pihak untuk tetap mematuhi peraturan yang telah disepakati.

\section{KESIMPULAN DAN IMPLIKASI KEBIJAKAN}

Keberadaan KKLD Gili Sulat dan Gili Lawang mempunyai beberapa jenis manfaat yaitu manfaat langsung ekstraktif perikanan, manfaat langsung non ekstraktif (pariwisata), perlindungan pantai dan estetika sumber daya. Nilai manfaat yang diperoleh dari keberadaan KKLD adalah sebesar Rp. 8.991.228.250 per tahun. Besarnya nilai manfaat menunjukkan pentingnya keberadaan KKLD Gili Sulat dan Gili Lawang.

Pengelolaan KKLD Gili Sulat dan Lawang mendapatkan dukungan pemerintah baik pusat maupun daerah. Selain itu, LSM lokal juga berperan aktif dalam kegiatan mendukung keberhasilan program KKLD Gili Sulat dan Gili Lawang. Walaupun demikian, optimalisasi pengelolaan KKLD merupakan suatu keharusan. Strategi optimalisasi pengelolaan KKLD Gili Sulat dan Gili Lawang dapat dicapai dengan mempertimbangkan komponen berikut : a) Manajemen data dan informasi; b) Pengelolaan batas dan zonasi; c) Pengelolaan sumber daya hayati dan perikanan; d) Pengelolaan sarana dan prasarana; e) Pengelolaan pariwisata, pendidikan dan penelitian; f) Pengendalian, monitoring dan pengawasan ; g) Pemberdayaan masyarakat; h) Penyadaran masyarakat; i) Penguatan kapasitas kelembagaan dan sumber daya manusia; j) Pengembangan jaringan kerjasama dan kemitraan; k) Sosialisasi dan penegakan hukum yang tegas.

\section{Implikasi Kebijakan}

Pemanfaatan dan pengelolaan KKLD Gili Sulat dan Gili Lawang sampai saat ini belum optimal dan perlu ditingkatkan sehingga dapat memberikan manfaat yang lebih besar kepada masyarakat. Beranjak dari kondisi tersebut maka sudah seharusnya setiap kebijakan yang diterapkan disosialisasikan kepada 
masyarakat dan diupayakan tidak menimbulkan kecemburuan atau konflik di masyarakat. Pelibatan masyarakat dalam pengelolaan KKLD dapat dilakukan dengan cara sosialisasi program, pendidikan dan pelatihan tentang manfaat KKLD, pendidikan dan pelatihan untuk mencari lapangan pekerjaan baru yang ramah lingkungan dan tidak mengganggu KKLD serta penyediaan alternatif mata pencaharian. Keterlibatan masyarakat dalam pengelolaan KKLD diharapkan dapat mengurangi biaya pengawasan yang dibebankan kepada APBD maupun APBN.

Seiring dengan upaya mengoptimalkan KKLD yang sudah ada dengan mempertimbangkan strategi yang tepat, replikasi KKLD pada tipologi dan lokasi lain merupakan hal yang mendesak sebagai langkah antisipatif dan responsif bagi keberlanjutan sumber daya perikanan pada khususnya dan sumber daya perairan pada umumnya.

\section{DAFTAR PUSTAKA}

Adrianto, L. 2006. Pengenalan Konsep dan Metodologi Valuasi Ekonomi Sumberdaya Pesisir dan Laut. PKSPL IPB. Bogor.

Anggraeni, E. 2006. Analisis Biaya Transaksi Usaha Penangkapan Ikan di Pelabuhan Ratu. Prosiding Seminar Nasional Sosial Ekonomi. Balai Besar Riset Sosial Ekonomi. Jakarta.
Cesar, H. 1997. Nilai Ekonomi Terumbu Karang Indonesia. The World Bank. Environment Department. $12 \mathrm{p}$.

Fauzi, A. 2003. The Economics Benefits of Marine Protected Areas, Reserves and Sanctuaris. Makalah disampaikan pada seminar bimbingan valuasi ekonomi kawasan konservasi laut. Bogor.

Koeshendrajana, S. 1997. Management Options for the Inland Fisheries Resource in South Sumatera, Indonesia. Disertasi. The University of New England. Australia. $238 p$.

Mulyana, Y dan A. Dermawan. 2008. Profil Konservasi Sumberdaya Ikan Kini dan Mendatang: Konservasi Kawasan Perairan Indonesia Bagi Masa Depan Dunia. Direktorat Konservasi dan Taman Nasional Laut, Direktorat Jenderal Kelautan Pesisir dan Pulau-Pulau Kecil. Departemen Kelautan dan Perikanan. Jakarta. 97 hal.

North, C. and R. P. Thomas. 1973. The Rise of the Western World: A New Economic History. Cambridge University Press. New York. 177 p.

Sain, B and R.W. Knecht. 1998. Integrated Coastal and Ocean Management: Concept and Practices. Island Press. Washington D.C. 